\title{
A rare case of hydrocele in a female
}

\section{Prachi Prabhakar Patil*, Meena Satia, V. Badhwar}

Department of Obstetrics and Gynecology, D. Y. Patil University, Nerul Navi Mumbai, Maharashtra, India

Received: 01 January 2019

Accepted: 05 February 2019

\section{*Correspondence:}

Dr. Prachi Prabhakar Patil,

E-mail: kpppsp@gmail.com

Copyright: (c) the author(s), publisher and licensee Medip Academy. This is an open-access article distributed under the terms of the Creative Commons Attribution Non-Commercial License, which permits unrestricted non-commercial use, distribution, and reproduction in any medium, provided the original work is properly cited.

\begin{abstract}
Vulval swellings have always been a case of a difficult and a puzzling situation and more so when they are huge in size. Vulvar swellings are of various types such as Bartholin cyst, sebaceous cyst, cyst of canal of nuck, inguino-labial hernia and vulval varicosities. Most common vulvar cysts are epidermal inclusion cysts. Usual location is beneath the epidermis. An alternative histogenesis is embryonic remnants or occlusion of pilosebaceous ducts of sweat glands. Cutaneous cysts which are lined by ciliated epithelium are very rare, and authors present a rare case of a cyst arising from a left labium majus resembling a hydrocele seen in males with histopathology suggestive of ciliated cyst of the vulva.
\end{abstract}

Keywords: Cutaneous cysts, Hydrocele, Vulval swellings

\section{INTRODUCTION}

Interest in vulvar disease has increased markedly. Literature search has shown the involvement of various specialties, including dermatology, genitourinary medicine, gynaecology and pathology. The involvement of multiple specialties reflects the complex nature of vulvar diseases and this necessitates the need of a team approach to the study of the vulva. The processes vaginalis of males is equivalent to the saccus vaginalis of females, extension of which into the inguinal canal is called 'canal of Nuck'.1

This is formed by the invagination of the parietal peritoneum coming with the round ligament which attaches to the vulva. ${ }^{2}$ Obliteration Of the canal occurs completely by the first year of life and if it persists may lead to inguinal hernia. ${ }^{3}$ Partial failure of obliteration may result in a cystic swelling called as 'hydrocele of the canal of Nuck' ${ }^{4}$ Excessive secretion of fluid from the lining epithelium of the peritoneum results in a cystic swelling. This could be either due to inflammation, trauma or due to inadequate lymphatic drainage. ${ }^{5}$ They are asymptomatic but when infected may cause intense pain and discomfort. Symptomatic cysts warrant removal Sometimes remnants of the paramesonephric ducts may also accompany the round ligament in its course to the attachment at the labia majora. An imbalance of fluid secretion and absorption by the peritoneal lining may lead to the development of a labial cyst as was seen in our patient.

\section{CASE REPORT}

A 24 years old patient a case of primary infertility since 6 years presented to Gynaecology OPD of D.Y. Patil Medical College a tertiary care centre for evaluation of infertility. After a thorough history taking about her menstrual cycle, marital and sexual history patient was taken up for examination.

On general examination she was averagely built and nourished with no external signs and stigmata of any congenital abnormalities. On examination there was a cystic swelling seen arising from the left labium majus which was $6 \times 6 \mathrm{~cm}$ in size. On palpation it was totally cystic with no solid components, no bowel was felt but trans-illumination test positive as shown in the Figure 1. 


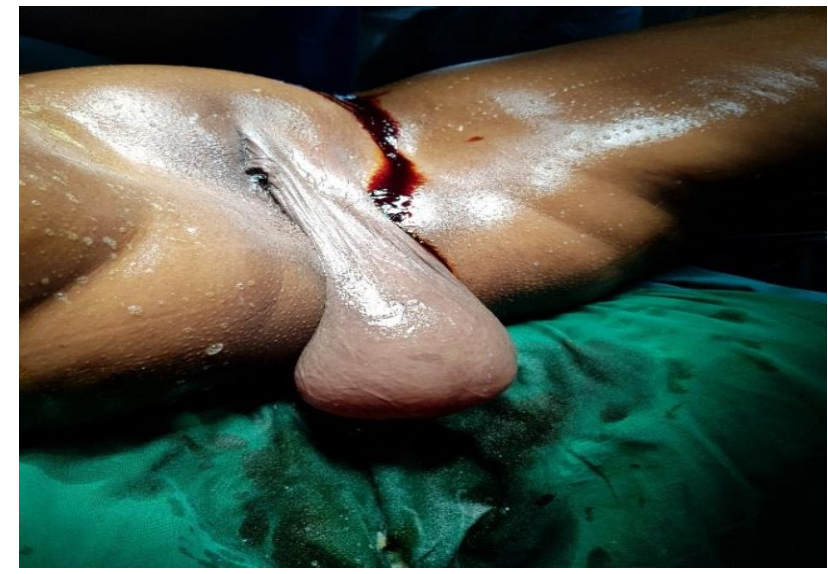

Figure 1: Clinical examination findings.

A clinical impression of the Hernia / Hydrocele from the canal of Nuck was made and patient was advised further investigations. An opinion from a general surgeon was taken to rule out any congenital abnormality /remnants of mesonephric ducts.

They opined it as a case of cystic non - reducible mass with no impulse on coughing most likely suggestive of a hydrocele of canal of nuck / encysted hydrocele. Patient was sent for sonography. On USG it appeared as a chronic fluid filled cyst with few internal echoes as shown in the Figure 2.

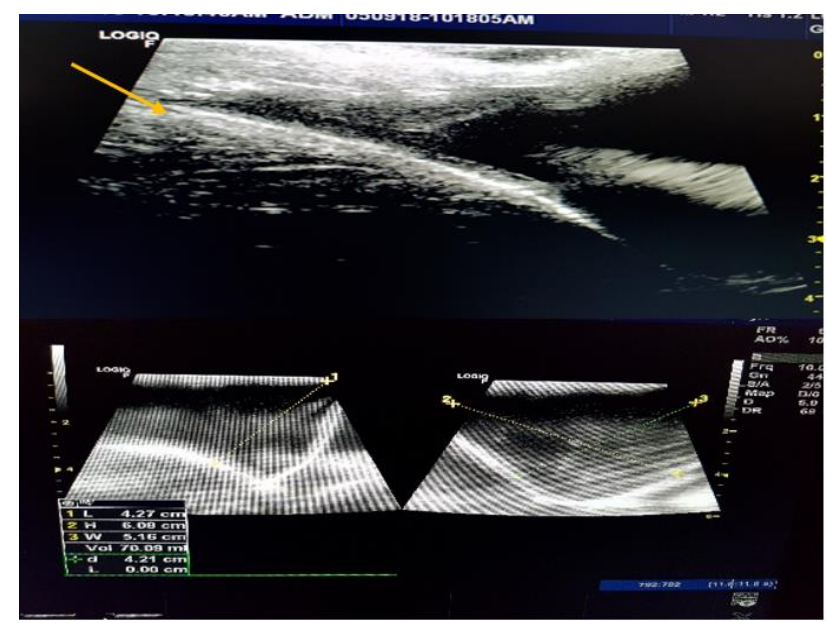

Figure 2: USG picture showing fluid filled cyst.

No fluid was seen coming through the canal of Nuck on coughing which meant it was a non-communicating cyst. After all the preoperative investigations and anaesthesia fitness patient was posted for labial cyst excision.

Intraoperative findings were as shown in Figure 3, Figure 4 and Figure 5. The cyst was separated, and excision was done along with redundant skin. Clear fluid was present within the cyst. There was no communication of cyst with abdominal cavity. Round ligament was palpable which was clamped cut and ligated and the specimen was sent to the pathologist for evaluation.

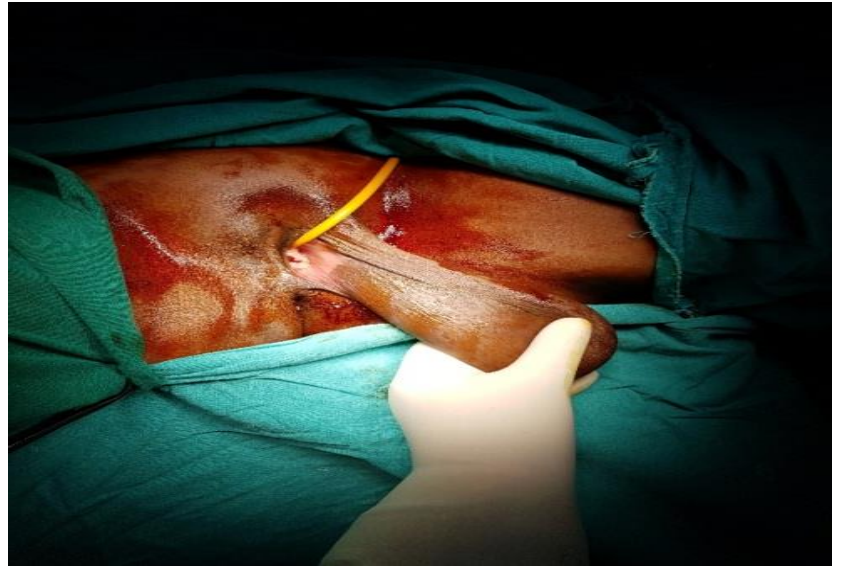

Figure 3: Preoperative.

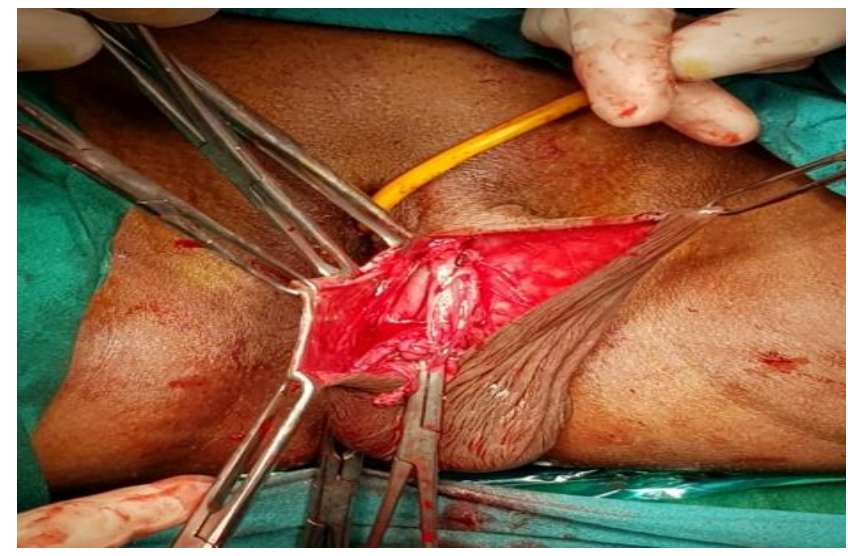

Figure 4: Intraoperative.

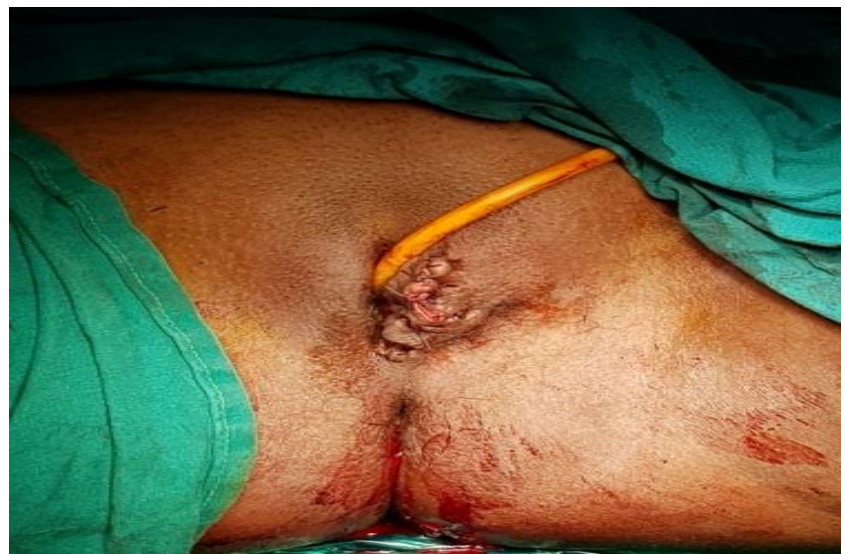

Figure 5: Postoperative

On histopathology the lining of the cyst wall was mesothelium with few columnar ciliated cells resembling the epithelial cells of the fallopian tubes as shown in the following Figure 6 and hence an impression of remnant of para-mesonephric ducts was made Immunohistochemistry was advised to find out whether these cells were ER/PR positive. The report showed that both stroma and epithelial cells were positive for estrogen and progesterone hence the final report of a rare entity of ciliated cyst of the vulva was given by the pathologist 
with the possibility of some remnants of the paramesonephritc ducts.

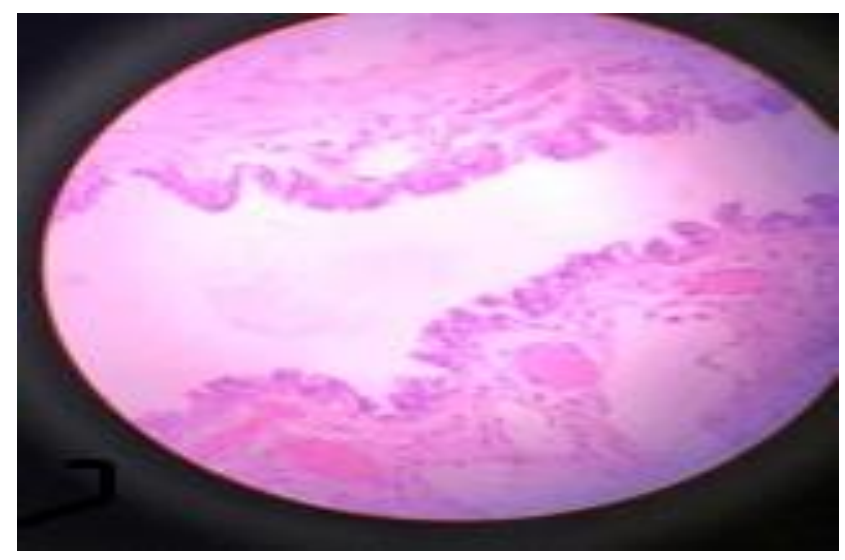

Figure 6: Histopathology findings of ciliated epithelium.

\section{DISCUSSION}

In clinical practice vulval swellings are very rarely encountered. ${ }^{6}$ Vulval haematoma, cold abscess, indirect inguinal hernia and very rarely cystic haemangioma, hydrocele of the canal of nuck could be the differential diagnosis for this condition. ${ }^{7,8}$ Paramesonephric cysts also called as ciliated cysts of the vulva are usually seen in young women of childbearing age. Presence of these in the vestibule occurs in very few cases..$^{9-11}$ Clinically, the cysts appears fluid filled, on the superior portion of the labia majora and measures around $1-5 \mathrm{~cm}$. The etiology is unknown; however, sequestration and migration of müllerian tissue during embryogenesis, dysontogenesis i.e. defective embryonic development and metaplasia have been suggested as mechanisms for the origin of the cyst. Of these hypotheses, Müllerian heterotopia has been most commonly proposed to be the basis of similar histo pathological features of the epithelium. ${ }^{12,13}$ The origination of this ciliated cyst of the vulva is not very clear although there are various theories proposed:

- Displacement of Müllerian duct remnants,

- Ciliated epithelial cell metaplasia. The lining epithelium of the cyst is composed mainly of:

- A single row

- Pseudostratified cuboidal and columnar cells.

The cyst wall consists of both epithelial and connective tissues. Misplacement of Müllerian duct tissue has been considered as the highly probable cause for the origin of this CCV. ${ }^{9-13}$ The fallopian tube is lined by a single layer of ciliated cells, non-ciliated columnar secretory cells and intercalated cells. Pseudostratified columnar or cuboidal cells which exhibited cilia on the luminar aspect, showing similar features to the fallopian tube histologically, and was hypothesized to be oestrogendependent as was seen in our case and also patient gave history of a small swelling since childhood which increased slowly after menarche which shows oestrogen dependent lesion. Müllerian heterotopia during embryogenesis in CCV was reported to rapidly increase in size during pregnancy, suggesting that these lesions are sensitive to hormonal stimulation. ${ }^{14}$ Epithelial cells in $\mathrm{CCV}$ demonstrated nuclear staining for oestrogen receptor. $^{15-18}$ Both epithelial and stromal cells were positive for oestrogen and progesterone was a strong support that hormonal stimulation plays a role in the development of these lesions. The present case is the confirmed case of $\mathrm{CCV}$ with the lining epithelium positive for ER and PR.

\section{CONCLUSION}

When a female of any age presents with inguinal / labial swelling, diagnosis of hydrocele of canal of Nuck should be considered regardless of its rarity. Thorough history taking and investigations will help in early diagnosis and facilitate surgical planning. The best line of treatment is complete surgical excision. The histopathological and immunohistochemical findings strongly support the hypothesis that Ciliated cyst of the vulva could be Müllerian heterotopia.

\section{Funding: No funding sources Conflict of interest: None declared Ethical approval: Not required}

\section{REFERENCES}

1. Kassem TW. Female Hydrocele of Canal of Nuck: CT Findings. Austin J Radiol. 2017;4(3):1075.

2. Anderson CC, Broadie TA, Mackey JE, Kopecky KK. Hydrocele of the canal of Nuck: ultrasound appearance. Am Surg. 1995;61(11):959-61.

3. Standring S. Grays Anatomy. 40th edition. The anatomical basis of clinical practice. London: Elsevier Churchill Livingstone. 2005; 1321.

4. Manjunatha YC, Beeregowda YC, Bhaskaran A. Hydrocele of the canal of Nuck: imaging findings. Acta Radiol Short Rep. 2012;1(3):1-3.

5. Stickel WH, Manner M. Female Hydrocele (Cyst of the canal of Nuck) Sonographic Appearance of Rare and Little-Known Disorder. J Ultrasound Med. 2004; 23(3):429-32.

6. Huang CS, Luo CC, Chao HC, Chu SM, Yu YJ, Yen JB. The presentation of asymptomatic palpable movable mass in female inguinal hernia. Eur $\mathbf{J}$ Pediatr. 2003;162(7-8):493-5.

7. De Meulder F, Wojciechowski M, Hubens G, Ramet J. Female hydrocele of the canal of Nuck: A case report. Eur J Pediatr. 2006;165(3):193-4.

8. Tubbs RS, Loukas M, Shoja MM, Salter EG, Oakes WJ. Indirect inguinal hernia of the urinary bladder through a persistent canal of nuck: Case report. Hernia. 2007;11(3):287-8.

9. Hart WR. Paramesonephric mucinous cysts of the vulva. Am J Obstet Gynecol 1970; 107(7):1079-84. 
10. Kang IK, Kim YJ, Choi KC. Ciliated cyst of the vulva. J Am Acad Dermatol. 1995;32:514.

11. Hamada M, Kiryu H, Ohta T, Furue M. Ciliated cyst of the vulva. Eur J Dermatol 2004;14(5):347-9.

12. Newland JR, Fusaro RM. Mucinous cyst of the vulva. Nebraska Med J 1991;76(9):307-10

13. True L, Golitz LE. Ciliated plantar cyst. Arch Dermatol. 1980;116(9):1066-7.

14. Anderson RGW, Hein CE. Estrogen dependent ciliogenesis in the chick oviduct. Cell Tiss Res 1976; 171(4):459-66.

15. Sickel JZ. Cutaneous ciliated cyst of the scalp: a case report with immunohistochemical evidence for estrogen and progesterone receptors. Am J Dermatopathol. 1994;16(1):76-9.
16. Fontaine DG, Lau H, Murray SK, Fraser RB, Wright Jr JR. Cutaneous ciliated cyst of the abdominal wall. Am J Dermatopathol. 2002;24(1):63-6.

17. Butterworth RGW, Stewart M, Clark JV. Heterotopic ciliated epithelium: Müllerian origin? Lancet 1970; 1(7661):1400-1.

18. Yokozaki H, Yanagawa E, Harada M, Tahara E. Cutaneous ciliated cyst of the right lower leg. Pathol Int. 1999;49(4):354-7.

Cite this article as: Patil PP, Satia M, Badhwar V. A rare case of hydrocele in a female. Int $\mathrm{J}$ Reprod

Contracept Obstet Gynecol 2019;8:1215-8. 